АЗАРОВ Артур Александрович - кандидат технических наук, доцент департамента политологии Финансового университета при Правительстве РФ (125993, Россия, г. Москва, ГСП-3, Ленинградский np-кm, 49; artur-azarov@yandex.ru)

БРОДОВСКАЯ Елена Викторовна - доктор политических наук, профессор департамента политологии Финансового университета при Правительстве РФ (125993, Россия, г. Москва, ГСП-3, Ленинградский пр-кт, 49); заведующий кафедрой социально-политических исследований и технологий Института истории и политики Московского педагогического государственного университета (119435, Россия, г. Москва, Малая Пироговская ул., 1/1; brodovskaya@inbox.ru)

ЛУКУШИН Владимир Андреевич - стажер лаборатории аналитики больших данных ВОФ молодых политологов «Дигория 2020»; студент факультета социальных наук и массовых коммуникаций Финансового университета при Правительстве РФ (125993, Россия, г. Москва, ГСП-3, Ленинградский np-кm, 49; lukushin@aol.com)

\title{
ЦИФРОВЫЕ СООБЩЕСТВА НОВЫХ ПОЛИТИЧЕСКИХ ПАРТИЙ В РОССИИ (2020 г.)
}

\begin{abstract}
Аннотация. В статье представлены результаты прикладного политического исследования электорального потенциала новых политических партий, продемонстрировавших возможности своих цифровых инфраструктур в период ЕДГ 2020. Методика исследования базируется на принципах социально-медийной предикативной аналитики и опирается на применение автоматизированных инструментов сбора и обработки открытых цифровых следов. В работе представлена методика оценки электорального потенциала политических партий, исходящая из измерения таких показателей, как уровень вовлеченности пользователей в партийные онлайн-сообщества, соответствие географии аудитории региональных сообществ обозначенной в них локализации, ботовость цифровых сообществ.

Ключевые слова: политические партии, политические коммуникации, электоральные кампании, цифровые следы, цифровые сообщества, цифровые инфраструктуры, социальные медиа
\end{abstract}

Исследование выполнено при финансовой поддержке РФФИ и ЭИСИ в рамках научного проекта № 20-011-31407 «Интернет-коммуникации российских политических партий: масштаб, содержание и динамика информационных потоков в социальных медиа».

Введение. В 2020 г. впервые в истории партийной системы постсоветской России цифровые инфраструктуры системных участников избирательных кампаний стали значимым фактором коммуникации с целевыми группами. Этому способствовали следующие обстоятельства: рост национальной интернет-аудитории, пандемия COVID-19, повышение конкуренции между устоявшимися парламентскими партиями и условно новыми партийными акторами.

Современная Россия является одним из лидеров мирового интернет-трафика1. В 2020 г. был зафиксирован очередной рекорд среднесуточного использования социальных медиа российскими пользователями, а доля активных цифровых пользователей приблизилась к 100 млн чел., охватывая 78\% взрослого населения. Примечательно, что число российских пользователей растет за счет людей старшего возраста ${ }^{2}$.

1 Digital in 2020. - We Are Social. Доступ: https://wearesocial.com/digital-2020 (проверено 14.01.2021).

2 Аудитория интернета в России в 2020 году. - Mediascope. Доступ: https://mediascope.net/ news/1250827/ (проверено 14.01.2021). 
Пандемия COVID-19 весной-летом 2020 г. способствовала апробации новых технологий, включая дистанционное голосование по поправкам к Конституции РФ, а также в рамках Единого дня голосования (далее - ЕДГ) в ряде субъектов федерации. Ограничения, связанные с COVID-19, поставили электоральный успех партийных акторов в зависимость от степени развитости их цифровых инфраструктур в социальных медиа. На примере ЕДГ заметен успех новых сил, сделавших ставку на интернет-коммуникацию с таргетными группами.

Теоретический обзор. В зарубежных исследованиях можно выделить несколько направлений, посвященных интернет-коммуникациям политических партий. Так, сложности адаптации политических партий к цифровым потребностям и ожиданиям электората отражены в наиболее многочисленной группе работ [Janssen, Kies 2005; Mascheroni, Mattoni 2013; Klinger 2013]. Применение политическими партиями цифровых коммуникаций для решения электоральных задач находится в центре внимания Р. Карлсен, Дж. Энли и др. [Karlsen 2011; Enli, Skogerbø 2013]. В научный оборот введено понятие гипермедийной кампании [Lilleker, Tenscher, Stětka 2015]. Б. Колснес выделяет три недостатка при общении с избирателями в Интернете: риск для репутации, негативное внимание СМИ и ограниченные ресурсы [Kalsnes 2016]. Н. Браунинг, К.Д. Свитсер исследуют то, как медиаповестка, партийные фреймы, черты кандидатов и коммуникация между политической организацией и общественностью влияют на репутацию партии [Browning, Sweetser 2020].

Среди отечественных исследователей обозначенных проблем прежде всего можно выделить Л.В. Сморгунова и Д.В. Чижова. По мнению Л.В. Сморгунова, использование вебсайтов и выход партийных акторов в социальные сети определили тенденцию их превращения в медиакоммуникационные партии с формированием расширенных партийных сетей [Сморгунов 2014]. Также одним из ведущих исследователей интернет-коммуникаций политических партий в России является Д.В. Чижов. В частности, он выделил базовые формы и инструменты интернет-коммуникации партийных акторов: официальные интернет-сайты политических партий; интернет-проекты - спутники политических партий; специальные и электоральные проекты, проекты по фандрайзингу; активность политических партий в социальных сетях, блогосфере и на форумах; интернет-телевидение, видеохостинги, вебинары [Чижов 2015].

Методология и методика исследования. Методология исследования имеет междисциплинарный характер и базируется на следующих теориях и подходах:

- сетевой подход, в частности акторно-сетевая теория Б. Латур, отражающая идею относительно формирования и усиления акторов, прежде всего, во взаимодействии в сети [Latour 2005];

- теория мягкого подталкивания Р. Талера, описывающая побуждение к изменению поведения без ограничения выбора [Талер, Санстейн 2017].

Методика исследования базируется на принципах социально-медийной предикативной аналитики, позволяющей провести детальный анализ практик партийных сообществ в онлайн-среде на основе поиска открытых цифровых следов в крупнейших социальных медиа посредством применения автоматизированных инструментов сбора и обработки данных. Выборочную совокупность составляют такие новые политические партии, продемонстрировавшие наличие потенциала в период ЕДГ 2020, как «Новые люди», «За правду», «Зеленая альтернатива». В рамках исследования используются: сервис аналитики цифровых сообществ Popsters (интервал выгруженных данных: 01.10.202031.12.2020), открытые инструменты $A P I$ социальной сети ВКонтакте, а также сервисы анализа поисковых запросов и новостных источников Google Trends и Яндекс.Метрика. Вспомогательным методом исследования является ивент- 
анализ, позволяющий интерпретировать динамические данные, полученные в ходе применения автоматизированных инструментов.

Результаты исследования. На начальном этапе исследования была проанализирована представленность новых партий в социальных медиа. Новые политические партии заметно отличаются от традиционных партийных акторов именно подходом к организации работы в цифровой среде. Несмотря на ограниченное число используемых соцмедиа (9 - «Новые люди», 7 - «За правду», 8 - «Зеленая альтернатива»), данные партии достигли высокого уровня вовлеченности аудиторий в их информационные потоки. Уровень вовлеченности учитывает реальную активность участников цифрового сообщества, выраженную в форме элементов обратной связи - лайков, репостов, комментариев. Применение автоматизированного инструмента Popsters позволило рассчитать средний уровень вовлеченности по каждому партийному сообществу (см. табл. 1). Результаты расчетов демонстрируют большую вовлеченность аудиторий в цифровых сообществах политических партий «Новые люди» $(7,2 \%)$ и «За правду» (6,9\%). Несмотря на небольшие показатели числа подписчиков и участников данных сообществ, уже имеющаяся аудитория партий - активная и «живая» - вовлечена в партийные информационные потоки. Такой характер вовлеченности пользователей достигается прежде всего за счет регулярности контента, его неформального характера, оперативности и актуальности, а также обеспечения соответствия аудитории администрируемых сообществ.

таблица 1

Уровень вовлеченности в цифровые сообщества новых партий, \%

\begin{tabular}{|l|c|}
\hline \multicolumn{1}{|c|}{ Партия } & Уровень вовлеченности \\
\hline «Новые люди» & 7,2 \\
\hline «За правду» & 6,9 \\
\hline «Зеленая альтернатива» & 3,0 \\
\hline
\end{tabular}

Помимо качественных характеристик контента, вовлеченность пользователей достигается благодаря обеспечению целостности информационного потока и возможностей переключения поведения пользователей из онлайна в офлайн. Для политических партий это принципиально важная задача, связанная с возможностью электоральной мобилизации (как и с электоральной демобилизацией, например в случае протестного голосования или бойкота выборов). Целостность информационного потока новых партий достигается за счет связи персональных аккаунтов партийных активистов, волонтеров и лидеров. Подобная модель характерна для всех трех новых партий. Связи, как правило, формируются от федерального сообщества к региональным, далее - к региональным лидерам и активистам, затем к волонтерам, а также узким тематическим страницам. Такая модель превращает цифровые сообщества в сетевые хабы, точки пересечения политической активности, в то время как основные коммуникационные процессы формируются через персональные аккаунты локальных лидеров мнений, активистов и руководителей.

Ключевым показателем качества функционирования партийных региональных сообществ является их аудитория. География аудитории региональных сообществ должна соответствовать его локализации в социальных медиа. Для оценки состояния обозначенного показателя были отобраны 30 региональных сообществ исследуемых партий в социальной сети ВКонтакте. При помощи 
открытых инструментов $A P I$ произведена фильтрация участников отобранных сообществ по месту проживания, далее рассчитан средний показатель соответствия локализации всех сообществ полученному результату по каждой партии (см. табл. 2). В результате, все три партии показали высокий процент соответствия аудитории региональным сообществам (в среднем 71\%). Нужно учитывать тот факт, что расчет проводился не только из числа пользователей, чей регион проживания открыто указан в личной анкете, но и на основании подписки на три и более крупных сообществ определенного региона/города, что значительно расширяет полученные результаты.

Следующей возможностью социальных медиа является генерация информационных поводов. Активные цифровые сообщества политических партий могут самостоятельно создавать события, распространяя необходимый контент, который является информационной базой для медиаресурсов.

Таблица 2

Оценка соответствия аудитории региональных сообществ их локализации

\begin{tabular}{|l|c|}
\hline \multicolumn{1}{|c|}{ Партия } & Соответствие, $\%$ \\
\hline «Новые люди» & 82,8 \\
\hline «За правду» & 69,8 \\
\hline «Зеленая альтернатива» & 62,6 \\
\hline
\end{tabular}

Проследить зависимость между социально-медийной активностью партий и освещением их деятельности в СМИ возможно, сопоставив статистические данные цифровых сообществ и поисковых систем (Яндекс и Google).

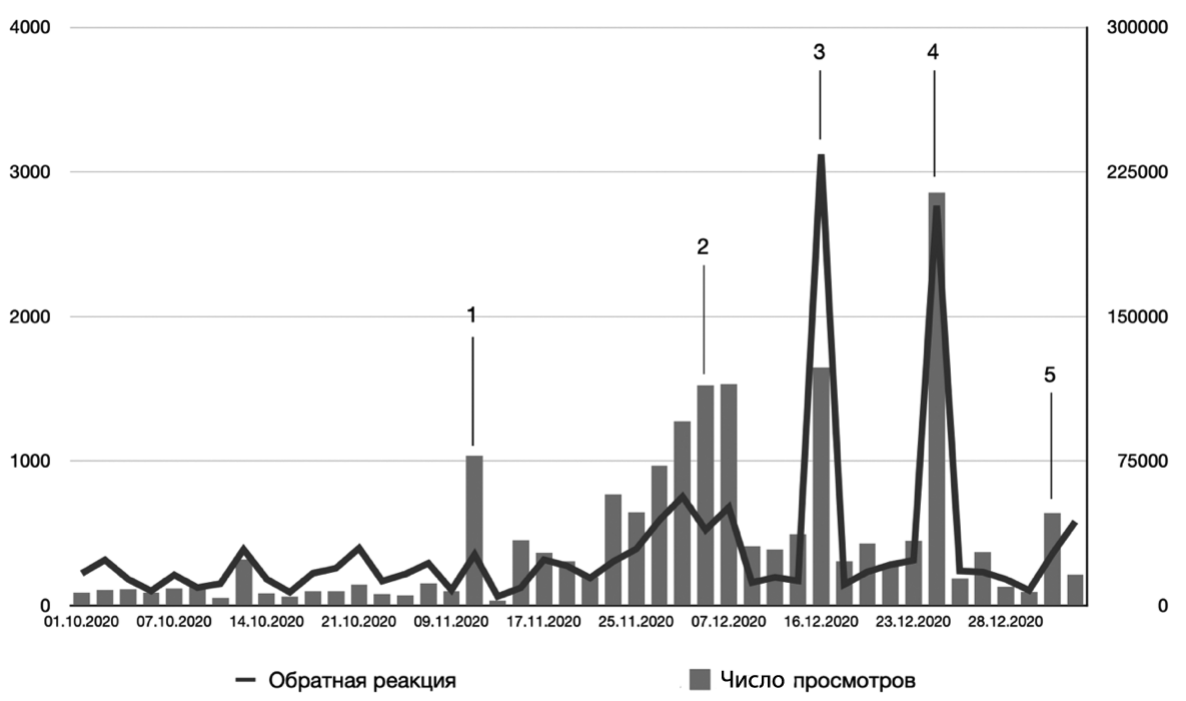

Рисунок 1. Характеристики цифровой активности партии «Новые люди»

На рис. 1 представлены данные по числу просмотров публикаций партии «Новые люди» в официальном сообществе социальной сети ВКонтакте и показатели обратной реакции пользователей в рассматриваемый период. 
Цифрами на графике отмечены пиковые значения упоминания партии на сайтах федеральных СМИ. Применение ивент-анализа позволило связать данные с конкретными событиями: 1 - открытие новых региональных отделений, 2 - объявление о сотрудничестве партии с известным технологом Е. Минченко, 3 - объявление о намерении партии участвовать в думской кампании 2021 г., 4 - пресс-конференция лидера партии А. Нечаева, 5 - публикация экспертных прогнозов по предстоящей кампании, публичная критика партией системы экологического мониторинга. В половине выгруженных информационных публикаций присутствуют ссылки на официальные страницы партии в социальных сетях.

Заключительным показателем, формирующим оценку качества управления цифровыми сообществами, является их ботовость - процент фейковых аккаунтов, имитирующих реальных людей среди участников сообществ. Процесс обнаружения современных ботов затруднен в силу их схожести со страницами реальных пользователей. Для оценки ботовости целесообразно совместное использование ручной обработки и автоматизированных инструментов, базирующихся на $A P I$. Для ручного анализа применяется формула вида $b-h>5$, где $b$ - расчетный показатель ботовости аккаунта, $h-$ расчетный показатель «человечности» (нефейковости), при этом изначальная оценка каждого аккаунта равна нулю. Показатель ботовости рассчитывается через формулу вида: $b=k_{1}+k_{2}+k_{3}+k_{4}$, где $k_{1}-$ удаленный аккаунт $(+20), k_{2}-$ заблокированный аккаунт $(+10), k_{3}-$ неактивный аккаунт $(+2), k_{4}-$ в персональной анкете не указано место проживания $(+0,5)$. Обратный показатель рассчитывается через формулу $h=h_{1}+h_{2}+h_{3}$, где $h_{1}-$ наличие уникального адреса страницы $(+2)$, $h_{2}-$ верификация аккаунта $(+20), h_{3}-$ наличие ссылок на аккаунты в других социальных медиа в анкете. В случае выполнения изначального неравенства профиль относится к ботам.

Автоматизированная система оценки выстроена таким образом, что сама отсеивает из случайной выборки тех участников сообществ, которые не соответствуют заданным критериям. Автоматизированный анализ позволяет отсеять страницы по тем критериям, которые сложно рассчитать вручную. В данном исследовании отсеивались страницы без заполненной анкеты, а также участвующие в подозрительных сообществах. По результатам анализа (см. табл. 3) можно сделать вывод о низком показателе ботовости цифровых сообществ новых партий. Процент ботов увеличивается пропорционально числу участников, при этом полное отсутствие ботов в сообществах невозможно в силу их открытости.

Таблица 3

Оценка уровня ботовости официальных сообществ новых партий

\begin{tabular}{|l|c|}
\hline \multicolumn{1}{|c|}{ Партия } & Уровень ботовости, \% \\
\hline «Новые люди» & 12,2 \\
\hline «За правду» & 7,3 \\
\hline «Зеленая альтернатива» & 6,9 \\
\hline
\end{tabular}

Заключение. Учитывая скорость появления и распространения сетевых платформ, многие политические игроки пытаются достичь максимального эффекта от репрезентации в цифровой среде. Подобная стратегия является малоэффективной, т.к. партии часто не соблюдают правила администрирования 
информационных потоков, в то время как число официальных аккаунтов не отражает качество политического менеджмента. Действительно, социальные медиа представляют широкие возможности для политических партий в ходе прямых коммуникаций с гражданами и формирования собственной цифровой инфраструктуры. Однако каждая платформа обладает набором отличительных характеристик, включая особенности преобладающей аудитории, формат возможного контента, технические характеристики. Кроме того, традиционные российские политические партии склонны использовать социальные медиа в качестве инструмента информирования, не используя потенциал онлайн-сервисов в процессе взаимодействия с конкретными группами пользователей и их вовлечения в партийную повестку.

На основе результатов проведенного исследования цифровых сообществ новых политических партий можно сделать следующие выводы.

Во-первых, лидером по управлению цифровыми сообществами среди новых партийных акторов является партия «Новые люди», сумевшая качественно организовать работу в социальных медиа. Она же обладает наибольшим среди рассматриваемых кейсов электоральным потенциалом на предстоящих в 2021 г. выборах.

Во-вторых, информационные потоки новых партий в социальных медиа управляются более качественно, чем в случае с традиционными партиями. Примеры интернет-коммуникации с таргетными группами таких партий, как «Новые люди» и «За правду», демонстрируют следование правилам коммуникационного менеджмента в социальных медиа: это обеспечение целостности информационного потока, превалирование неформального контента над формальным, превалирование неполитического контента над политическим, адресность информационных касаний и др.

$\mathrm{K}$ перспективным направлениям исследования можно отнести разработку социальных графов крупных региональных сообществ новых партий, а также персональных страниц локальных партийных активистов и лидеров; анализ социально-медийных профилей участников официальных сообществ новых политических партий с применением автоматизированных инструментов; оценку взаимодействия администрируемых сообществ с пользователями для составления рекомендаций по совершенствованию партийного менеджмента в цифровой среде.

\section{Список литературы}

Сморгунов Л.В. 2014. Сетевые политические партии. - Полис. Политические исследования. № 4. С. 21-37.

Талер Р., Санстейн К. 2017. Nudge. Архитектура выбора. Как улучшить наши решения о здоровье, благосостоянии и счастье. М.: Манн, Иванов и Фербер. $310 \mathrm{c.}$

Чижов Д.В. 2015. Интернет-коммуникации политических партий: типологические черты и инструменты. - Информационное общество. № 4. С. 46-61.

Browning N., Sweetser K.D. 2020. How Media Diet, Partisan Frames, Candidate Traits, and Political Organization-public Relationship Communication Drive Party Reputation. - Public Relations Review. Vol 6. Is. 2. P. 1-17.

Enli G.S., Skogerbø E. 2013. Personalized Campaigns in Party-centered Politics. Information, Communication and Society. Vol. 16. Is. 5. P. 757-774.

Janssen D., Kies R. 2005. Online Forums and Deliberative Democracy. - Acta Politica. Vol. 40. Is. 3. P. 317-335.

Kalsnes B. 2016. The Social Media Paradox Explained: Comparing Political Parties' Facebook Strategy Versus Practice. - Social Media + Society. Vol. 2. Is. 2. P. 1-11. 
Karlsen R. 2011. Velgernes valgkamp. - Det politiske landskapet: En studie av stortingsvalget 2009 [The Political Landscape. A Study of the National Election 2009]. Oslo: Cappelen Damm Akademisk. P. 41-64.

Klinger U. 2013. Mastering the Art of Social Media. - Information, Communication and Society. Vol. 16. Is. 5. P. 717-736.

Latour B. 2005. Reassembling the Social: An Introduction to Actor-Network-Theory. N.Y.: Oxford University Press. 301 p.

Lilleker D. G., Tenscher J., Štětka V. 2015. Towards Hypermedia Campaigning? Perceptions of New Media's Importance for Campaigning by Party Strategists in Comparative Perspective. - Information, Communication and Society. Vol. 18. Is. 7. P. 747-765.

Mascheroni G., Mattoni A. 2013. Electoral Campaigning 2.0 - The Case of Italian Regional Elections. - Journal of Information Technology \& Politics. Vol. 10. Is. 2. P. 223-240.

\footnotetext{
AZAROV Artur Aleksandrovich, Cand.Sci.(Tech.Sci.), Associate Professor of the Department of Political Science, Financial University under the Government of the Russian Federation (49 Leningradsky Ave, GSP-3, Moscow, Russia, 1259930)

BRODOVSKAYA Elena Viktorovna, Dr.Sci. (Pol.Sci.), Professor of the Department of Political Science, Financial University under the Government of the Russian Federation (49 Leningradsky Ave, GSP-3, Moscow, Russia, 1259930); Head of the Chair of Socio-Political Research and Technology, Institute of History and Politics, Moscow State Pedagogical University (1/1 Malaya Pirogovskaya St, Moscow, Russia, 119435; brodovskaya@inbox.ru)

LUKUSHIN Vladimir Andreevich, intern of the Big Data Analytics Laboratory of «Digoria 2020» Scientific Forum; student of the Faculty of Social Sciences and Mass Communications, Financial University under the Government of the Russian Federation (49 Leningradsky Ave, GSP-3, Moscow, Russia, 1259930; lukushin@aol.com)
}

\title{
DIGITAL COMMUNITIES OF NEW POLITICAL PARTIES IN RUSSIA (2020)
}

\begin{abstract}
The article presents the results of an applied political study of the electoral potential of new political parties that have demonstrated the capabilities of their digital infrastructures during the Russian Election Day 2020. The research methodology is based on the principles of social media predictive analytics and relies on automated tools for collecting and processing open digital traces. The paper presents a methodology for assessing the electoral potential of political parties, based on the measurement of indicators such as the level of user involvement in online party communities, the correspondence of the geography of the audience of regional communities to the localization indicated in them, and the bots of digital communities.
\end{abstract}

Keywords: new parties, political parties, political communications, digital environment, digital communities, social media, social media analysis 